NBER WORKING PAPER SERIES

\title{
SEASONAL ADJUSTMENT OF NIPA DATA
}

Jonathan H. Wright

Working Paper 24895

http://www.nber.org/papers/w24895

\author{
NATIONAL BUREAU OF ECONOMIC RESEARCH \\ 1050 Massachusetts Avenue \\ Cambridge, MA 02138 \\ August 2018
}

The views expressed herein are those of the author and do not necessarily reflect the views of the National Bureau of Economic Research.

NBER working papers are circulated for discussion and comment purposes. They have not been peer-reviewed or been subject to the review by the NBER Board of Directors that accompanies official NBER publications.

(C) 2018 by Jonathan H. Wright. All rights reserved. Short sections of text, not to exceed two paragraphs, may be quoted without explicit permission provided that full credit, including ( $)$ notice, is given to the source. 
Seasonal Adjustment of NIPA data

Jonathan H. Wright

NBER Working Paper No. 24895

August 2018

JEL No. C32,E01

\begin{abstract}
$\underline{\text { ABSTRACT }}$
In the 2018 comprehensive update of the national income and product accounts, the Bureau of Economic Analysis released not seasonally adjusted data, and modified its seasonal adjustment procedures. I find some indication of residual seasonality in the seasonally adjusted data as published before this update. The evidence for residual seasonality is weaker in the seasonally adjusted data after the update. I also directly seasonally adjusted the aggregate not seasonally adjusted data, and this entirely avoids residual seasonality. The average absolute difference between my seasonally adjusted real GDP data and the current official published version is 1.1 percentage points in quarter-over-quarter annualized growth rates.
\end{abstract}

Jonathan H. Wright

Department of Economics

Johns Hopkins University

3400 N. Charles Street

Baltimore, MD 21218

and NBER

wrightj@jhu.edu

A data appendix is available at http://www.nber.org/data-appendix/w24895 


\section{Introduction}

In the 2018 comprehensive update of the national income and product account (NIPA) data, the Bureau of Economic Analysis (BEA) made changes to the method for seasonal adjustment and began publishing quarterly not seasonally adjusted (NSA) data, both current and chained dollar, for GDP and its major components going back to 2002. ${ }^{1}$ This is part of an overhaul of seasonal adjustment procedures being undertaken by BEA, as discussed in McCulla and Smith (2015) and Moulton and Cowan (2016). These are very welcome developments. In particular, the publication of NSA data is an enormous advance in transparency. Data users will naturally question how the BEA and the agencies that provide data to the BEA undertake seasonal adjustment. These users will now be able to seasonally adjust the data themselves, at least at the level of aggregation at which the data are published. NIPA data are one of the great advances in economic analysis of the 20th century ${ }^{2}$, and macroeconomic data generally exhibit seasonal fluctuations of comparable amplitude to the business cycle. This makes it very valuable for economists to have the source data necessary for studying the seasonal patterns in NIPA data. ${ }^{3}$ Moreover, the unadjusted data may be useful sources of identification in macroeconomic models (Ghysels, 1988; Barsky and Miron, 1989; Hansen and Sargent, 1993; Sims, 1993; Saijo, 2013). The practice of statistical agencies releasing only seasonally adjusted data has been criticized by a number of authors including Maravall (1995) and Wright (2013).

Unlike many other economic statistics, seasonal adjustment of the NIPA data is not all conducted by one agency. Although BEA compiles the NIPA data, many of the data come in the door of BEA already seasonally adjusted by other agencies, such as the Census Bureau. To compile the NSA data, BEA had to go back to those other agencies to request unadjusted data. The

\footnotetext{
${ }^{1}$ BEA had in the past published current dollar NSA data, but ceased doing so in 2008 as a cost cutting measure. The new data consist of nominal, real and price series for GDP and its major components. I do not attempt to use the old data, because my focus in this paper is on real data and to some extent on price indices.

${ }^{2}$ See Landefeld, Seskin, and Fraumeni (2008) for a discussion of NIPA history and methods.

${ }^{3}$ Until now, researchers worried about the adequacy of seasonal adjustment have been forced to undertake a double seasonal adjustment—-seasonally adjusting the seasonally adjusted data (Rudebusch, Wilson, and Mahedy, 2015; Boldin and Wright, 2016; Phillips and Wang, 2016). But working with the NSA data is clearly better.
} 
process of compiling NSA data was therefore much more cumbersome than one might initially suppose. Also, the decentralized nature of NIPA seasonal adjustment means that it is not documented or replicable by outside researchers in the same way as seasonal adjustment in other macroeconomic data, such as the BLS establishment survey.

Figure 1 plots the level of topline real GDP data without seasonal adjustment. A sawtooth seasonal pattern can clearly be seen where the level of GDP typically drops about 3 percentage points (not at an annualized rate) in the first quarter, and rebounds in the rest of the year. Thus, in the raw data, there is a drop in output of comparable magnitude to a recession every winter.

In this note, I compare three different sets of NIPA numbers. The first are the data as seasonally adjusted by BEA just before the recent update. The second are the data as seasonally adjusted by BEA after the update. Of course, the change in seasonal adjustment methodology was just a part of the 2018 benchmark revision. In the third dataset, I take the NSA data as now published by the BEA and seasonally adjust them using TRAMO-SEATS, which is based on a seasonal ARIMA model, as opposed to the moving average filters that are the mainstay of seasonal adjustment in North America. ${ }^{4}$ This approach differs from that used in official NIPA seasonal adjustment in a number of ways. Notably, the official seasonal adjustment is done at the disaggregate level (the indirect approach), whereas I instead do the seasonal adjustment at the aggregate level (the direct approach). The indirect approach has the advantage that the aggregate data are exactly the sum of the disaggregate components. This is lost with the direct approach. ${ }^{5}$ On the other hand, seasonal adjustment at the disaggregate level might be more prone to leaving residual seasonality in aggregate data. This can arise from sources including:

1. Some of the components are not seasonally adjusted at all on the grounds that the seasonality in those components is not sufficiently pronounced. There may be many components that each exhibit minor seasonality where that seasonality is however positively correlated across the components. The omitted seasonality may therefore be quite con-

\footnotetext{
${ }^{4}$ See Wright (2017) for arguments for using an ARIMA-based parametric approach to seasonal adjustment.

${ }^{5}$ It is lost in any case when using chained dollar data.
} 
sequential in the aggregate, even if it was not at the component level.

2. Monthly series may be deemed to have no seasonality and are consequently not seasonally adjusted at all, but there may be a material seasonal pattern after aggregation to the quarterly frequency (Moulton and Cowan, 2016).

3. Revision policies preventing seasonal adjustments being applied to historical data. The latest benchmark revision has softened, but not eliminated, these revision policies.

4. BEA intentionally avoids seasonally adjusting series related to government policy even where seasonal effects are believed to be present, to make the effects of policy more transparent (Moulton and Cowan, 2016).

The possibility of residual seasonality being created from an interaction of pre-testing with aggregation is heightened by the Census Bureau guideline that a series should not be seasonally adjusted unless the F-statistic for seasonality exceeds 7 (McDonald-Johnson, Monsell, Fescina, Feldpausch, Hood, and Wroblewski, 2010). ${ }^{6}$

In my implementation of TRAMO-SEATS, I use the automatic ARIMA model selection method of Gómez and Maravall (1996, 2013). I incorporate Easter and trading day effects within the TRAMO-SEATS program, and use all the available NSA data back to 2002 for the seasonal adjustment. Modeling choices in seasonal adjustment are of course very consequential, but this seems to be a reasonable benchmark.

The plan for the remainder of this paper is as follows. In section 2, I report the alternative seasonally adjusted series. In section 3, I test for residual seasonality in these series. Section 4 concludes.

\footnotetext{
${ }^{6}$ See Maravall (2006) and Chapter 8 of Bloem, Dippelsman, and Mæhle (2001) for more discussion of the direct and indirect approaches.
} 


\section{Alternative series}

The series that I consider in this paper are as follows: GDP, personal consumption expenditures, nondurable goods, durable goods, services, gross private domestic investment, equipment, structures intellectual property investment, residential investment, exports, imports, government spending, federal defense and non-defense spending and state and local government spending, all in chained dollars, as well as the GDP, personal consumption expenditures (PCE) and core PCE price indices. The internet appendix to this paper gives the levels of all of these 19 series with all of the approaches to seasonal adjustment. ${ }^{7}$ The NSA data does not include core PCE, and so this is excluded from the directly seasonally adjusted series.

The average absolute difference between the current official data on real GDP quarter-overquarter growth rates and my direct seasonal adjustment is 1.1 percentage points at an annualized rate. Table 1 reports growth rates for real GDP back to 2014 using the three approaches to seasonal adjustment. In 2018, real GDP growth rates in the first two quarters are 3.1 and 4.0 percentage points respectively, as opposed to 2.2 and 4.1 percentage points in the published data.

Table 2 reports the average growth rates since 2002Q1 in each of the four quarters for all of these series and with all of the approaches to seasonal adjustment. Here and throughout, I use the post-2002 sample period to accord with the availability of NSA data.

Apparent seasonal patterns can be seen in many of the seasonally adjusted series as published before the 2018 benchmark revision. For example, the average growth rate of real GDP in the first quarter was 1.1 percentage points, more than one percentage point lower than the average for the other quarters of the year. Particular first-quarter weakness can be seen in federal defense spending. This pattern of weakness in first quarter GDP growth and some of its com-

\footnotetext{
${ }^{7}$ The first two methods of course involve no seasonal adjustment on my part; they are just reporting the data as published by the BEA.
} 
ponents was noticed by Wall Street economists and the press ${ }^{8}$, and has been written about extensively (Stark, 2015; Rudebusch, Wilson, and Mahedy, 2015; Gilbert, Morin, Paciorek, and Sahm, 2015; Groen and Russo, 2015; Phillips and Wang, 2016; Lunsford, 2017). The finding of a particularly strong negative first quarter effect in federal defense spending is a common theme of much of this existing work. There is also some sign of residual seasonality in price indices, with core PCE inflation running a little higher in the first half of the year than the second half of the year, as found earlier by Peneva (2014).

There is less sign of residual seasonality in the data as published in the 2018 benchmark revision. The average growth rate in the first quarter was revised up to 1.5 percentage points, closer to but still lower than the average for the other quarters of the year. The first quarter effect in federal defense spending has disappeared. Meanwhile, there is no sign of residual seasonality in the directly seasonally adjusted data. Although first quarter real GDP growth is on average higher with the TRAMO-SEATS directly seasonally adjusted data than in the published numbers, in individual years the first quarter reading using the direct seasonal adjustment is sometimes higher and sometimes lower.

Table 2 reports some summary statistics for the growth rate series with the three different approaches to seasonal adjustment. The summary statistics are the sample standard deviation abd the first and fourth sample autocorrelations. These summary statistics are mostly similar before and after the benchmark revision, but the benchmark revision generally slightly reduced the fourth autocorrelation, consistent with better seasonal adjustment. Comparing the post-revision published data with the directly seasonally adjusted data, the directly seasonally adjusted data are typically more persistent in the sense that the first autocorrelation is higher. This is particularly true for consumption (where the coefficient goes from 0.51 in the published data to 0.86 in the directly adjusted data) and durables (where the coefficient goes from 0.14 to

\footnotetext{
${ }^{8}$ Alec Phillips of Goldman Sachs was one of the first to highlight the phenomenon. See also a CNBC article by Steve Liesman https://www.cnbc.com/2015/04/21/the-mysterious-case-of-weak-1q-gdp-for-30-years.html.
} 
0.50). This suggests that the directly seasonally adjusted data might be easier to forecast. ${ }^{9}$

\section{Testing for statistical significance}

The seasonal adjustment approach is clearly important. The low level of average real GDP growth in the first quarter raises a suspicion of residual seasonality in the pre-benchmark revision official data and still, to a lesser extent, in the post-benchmark revision data. But it is useful to have a formal test for remaining seasonal patterns in the seasonally adjusted data. I take an approach following Canova and Hansen (1995). Let $y_{t}$ be any seasonally adjusted series, and let $D_{j t}$ be a dummy that is 1 if quarter $t$ is in the $j$ th quarter of the year and 0 otherwise. Consider the regression:

$$
y_{t}=\alpha+\rho y_{t-1}+\beta_{1} D_{1 t}+\beta_{2} D_{2 t}+\beta_{3} D_{3 t}+\varepsilon_{t}
$$

Consider a Wald test of the hypothesis that $\beta_{1}=\beta_{2}=\beta_{3}=0$. In this Wald test, I use Newey-West standard errors, while the inclusion of a lag in equation (3.1) serves as a form of pre-whitening. This approach to testing for residual seasonality differs from the F-test in the X-13 seasonal adjustment process in that a lagged dependent variable is included and heteroskedasticity and autocorrelation robust standard errors are used, whereas the X-13 uses the ordinary F-statistic with a critical value of 7 as a more informal adjustment for omitted heteroskedasticity and serial correlation (McDonald-Johnson, Monsell, Fescina, Feldpausch, Hood, and Wroblewski, 2010). Following the advice of Lazarus, Lewis, Stock, and Watson (forthcoming), the lag truncation parameter is set to $1.3 T^{1 / 2}$ (rounded to the nearest integer) where $T$ is the sample size and the non-standard "fixed b" critical values of Kiefer and Vogelsang (2005) are used.

Table 4 reports the Wald test $p$-values for each series and each method of seasonal adjustment,

\footnotetext{
${ }^{9}$ This is purely speculative-these TRAMO-SEATS seasonally adjusted data use a two-sided filter and were not available in real time.
} 
over the post-2002 sample. In the series as published by BEA before the benchmark revision, there is significant residual seasonality at the 5 percent level in structures and federal defense spending alone. The $p$-value for real GDP is 0.18 .

Thus, although the residual seasonality in the pre-revision data appears economically significant, it is typically not statistically significant at conventional levels, with some exceptions. Existing work has generated mixed conclusions regarding the statistical significance of residual seasonality, with results sensitive to the precise testing methodology and sample period. Stark (2015), Rudebusch, Wilson, and Mahedy (2015) and Lunsford (2017) conclude that there is important residual seasonality, while Gilbert, Morin, Paciorek, and Sahm (2015) and Groen and Russo (2015) are more skeptical.

Where we fail to reject the null hypothesis of no residual seasonality, it is possible that the apparent residual seasonality is a "fluke", caused for example by unusual weather. Temperatures in the first quarter have been below their 30-year historic average in the first quarter for 13 out of the last 17 years, using the updated dataset of Boldin and Wright (2016). ${ }^{10}$ But it is also possible than the residual seasonality is real, but the power of the test is insufficient to detect it. To illustrate this I did a small Monte-Carlo simulation. The design is:

$$
y_{t}=z_{t}+s_{t}
$$

where

$$
z_{t}=0.4 z_{t-1}+\varepsilon_{t}
$$

$\varepsilon_{t}$ is iidN $(0,5)$ and

$$
\begin{aligned}
& s_{t}=-\theta, t=1,5,9, . . \\
& s_{t}=\frac{\theta}{3}, t \neq 1,5,9, . .
\end{aligned}
$$

\footnotetext{
${ }^{10}$ However, federal defense spending might seem an unlikely component to be heavily influenced by unusually cold winters.
} 
The innovation variance and persistence are designed to be representative of post Great Moderation real GDP growth data, in annualized quarter-over-quarter percentage changes, while $s_{t}$ represents a simple form of omitted deterministic seasonality. The parameter $\theta$ can be thought of as representing the magnitude of a potential negative first quarter effect.

I simulated the power of the Wald test based on equation (3.1) when applied to these data with varying values of $\theta$ and a sample size of $T=64$, corresponding to 16 years of data. The power curve for a 5 percent nominal test size is plotted in Figure 2. A value of $\theta$ of 1 , corresponding to quarter-over-quarter growth in one quarter being lower than the year-average by 1 percentage point at an annualized rate has a probability of being detected of a bit less than 40 percent. Thus a degree of residual seasonality that seems economically quite significant might fail to be detected. Estimation and hypothesis testing are quite distinct problems, and from a decision theoretic perspective, the fact that a parameter is not statistically significantly different from zero should not lead one to view zero as the best guess for that parameter, especially when the power of the test is low. In the same way, I think that it is unwise to walk away from the apparent residual seasonality in pre-revision data even in cases where it is not statistically significant at conventional significance levels. This is especially true since the power of the test is low, and there is reason to expect at least some residual seasonality given the construction of the published seasonally adjusted numbers, as discussed in the introduction. The point estimate indicates that there was material residual seasonality in the BEA data as published before the benchmark revision, although the magnitude of that residual seasonality is hard to determine with much precision.

In the post-revision data (second column of Table 4), residual seasonality is still statistically significant at the 5 percent level for structures and is now statistically significant for equipment. The $p$-value for topline GDP is $\mathbf{0 . 6 6}$, and the residual seasonality is not significant for federal defense.

In the directly seasonally adjusted data (last column of Table 4), residual seasonality is statis- 
tically insignificant at the 10 percent level in every case. In fact the $p$-values are mostly close to 1 , indicating that the Wald statistic is typically in the left tail of the asymptotic distribution, but this makes sense because the series being tested were directly constructed to purge any seasonal pattern.

\subsection{Time-varying residual seasonality}

Existing evidence (e.g. Moulton and Cowan (2016)) indicates that the potential seasonal patterns in seasonally adjusted data are somewhat sensitive to the sample period. To some extent, this is not surprising. For one thing, in 2015 the BEA revised its seasonal adjustment procedures but applied the modified procedures only to data starting in 2012 (McCulla and Smith, 2015). After the 2018 benchmark revision, revisions to seasonal adjustment were extended further back in time, but with time spans that vary by component. All this means that there has to be at least some instability in seasonal patterns in the published seasonally adjusted data, both before and after the 2018 benchmark revision.

One can formally test for the stability of seasonal patterns using the approach of Canova and Hansen (1995) who apply the test of Nyblom (1989) to assess the stability of the $\beta$ coefficients in equation (3.1). The test statistic is:

$$
L=\frac{1}{T^{2}} \Sigma_{t=1}^{T} \Sigma_{i=1}^{t} z_{i}^{\prime} \hat{\Omega}^{-1} \Sigma_{i=1}^{t} z_{i}^{\prime}
$$

where $z_{i}=\left(D_{1 i} e_{i}, D_{2 i} e_{i}, D_{3 i} e_{i}\right)^{\prime}, e_{i}$ is the residual from equation (3.1), $\hat{\Omega}=\hat{\Gamma}(0)+\sum_{j=1}^{M} \frac{M+1-j}{M+1}(\hat{\Gamma}(j)+$ $\left.\hat{\Gamma}(j)^{\prime}\right)$ and $\hat{\Gamma}(j)=T^{-1} \Sigma_{t=1}^{T-j} z_{t} z_{t+j}^{\prime}$. I report the $p$-values in Table 5, over the period 2002Q12018Q1 using the three seasonally adjusted series. However, as before, in the Newey-West estimate of the variance-covariance matrix, I set the lag truncation parameter $M$ to $1.3 T^{1 / 2}$, and use nonstandard "fixed b" critical values. Cho and Vogelsang (2017) derive the limiting distribution of the sup- $F$ structural stability test using "fixed-b" asymptotics and by the same arguments 
under standard assumptions:

$$
L \rightarrow L^{*} \equiv \int_{0}^{1} \tilde{B}(r)^{\prime} \Omega^{-1} \tilde{B}(r) d r
$$

where

$$
\Omega=\frac{2}{b} \int_{0}^{1} \tilde{B}(s) \tilde{B}(s)^{\prime} d s-\frac{1}{b} \int_{0}^{1-b}\left[\tilde{B}(s) \tilde{B}(s+b)^{\prime}+\tilde{B}(s) \tilde{B}(s+b)\right]^{\prime} d s
$$

$\tilde{B}(r)=B(r)-r B(1), B(r)$ is a Brownian motion ( $3 \times 1$ in this case) and $b=\lim _{T \rightarrow \infty} M / T$. This is the distribution that is used to provide the $p$-values in Table 5.

In the series as published by BEA before the benchmark revision, there is significant timevariation in the residual seasonality at the 5 percent level in consumption, durables and federal defense spending, and at the 10 percent level in the GDP price index. Rejection of the hypothesis of constant seasonality implies residual seasonality in at least some part of the sample. After the benchmark revision, it is significant at the 5 percent level only for durables, and at the 10 percent level for consumption. With directly seasonally adjusted data, it is significant only for the PCE price index.

\subsection{Joint testing for stable and zero residual seasonality}

If the seasonal adjustment procedure works as one would hope, the coefficients $\beta_{1}, \beta_{2}$ and $\beta_{3}$ should be both constant and equal to zero, when applied to seasonally adjusted data. The Wald test (Table 4) tested that they were zero and the stability test (Table 5) tested that they were constant. To test the joint hypothesis, I consider the sum of the stability test and the Wald test, $L+W$, where $W$ denotes the Wald test statistic in equation (3.1). The asymptotic distribution of this joint test statistic is:

$$
L^{*}+B(1)^{\prime} \Omega^{-1} B(1)
$$

Table 6 shows the $p$-values from comparing the joint test with this asymptotic distribution over 
the period 2002Q1-2018Q1, again using the three seasonally adjusted series. The idea of this test is similar to combining the tests for stable and moving seasonality as considered by Lothian and Morry (1978), but the specific inference procedure discussed here is new, as far as I know.

In the series as published by BEA before the benchmark revision, the joint hypothesis is rejected at the 5 percent level for structures and federal defense spending. After the benchmark revision, the hypothesis is rejected at the 5 percent level only for equipment. With directly seasonally adjusted data, it is not rejected for any series.

\section{Conclusions}

Before the 2018 benchmark revision, there was some indication of residual seasonality in GDP and some of its components. The evidence for residual seasonality is weaker after the update. Because the BEA now publishes not seasonally adjusted data, users can now directly seasonally adjust the data themselves. This effectively eliminates concerns about residual seasonality. 
Figure 1: NSA Real GDP: 2002Q1-2018Q2

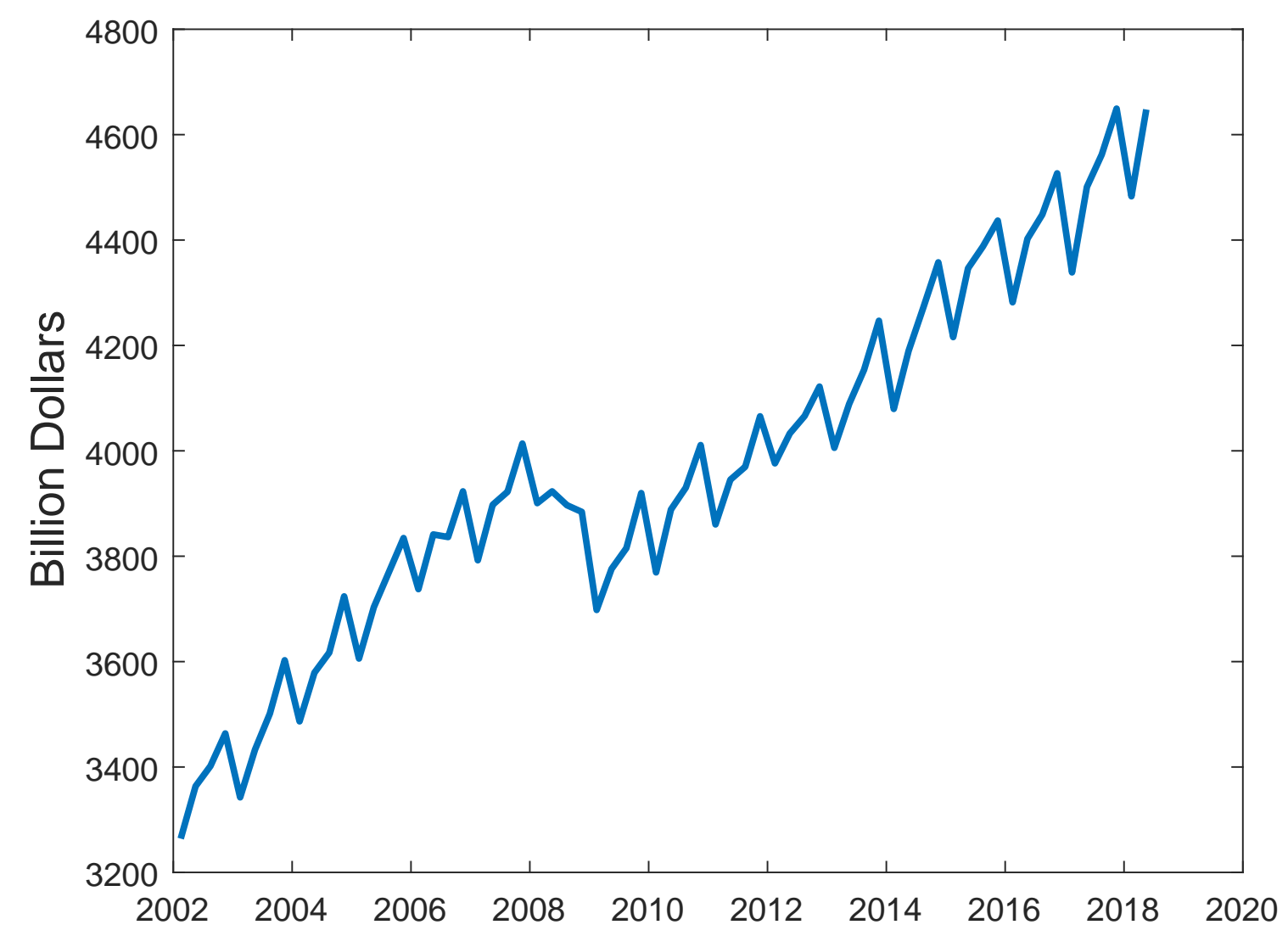

Notes: This figure plots the level of NSA GDP in billions of chained 2012 dollars at a quarterly rate. 
Figure 2: Simulated Power Curve of Residual Seasonality Wald Test

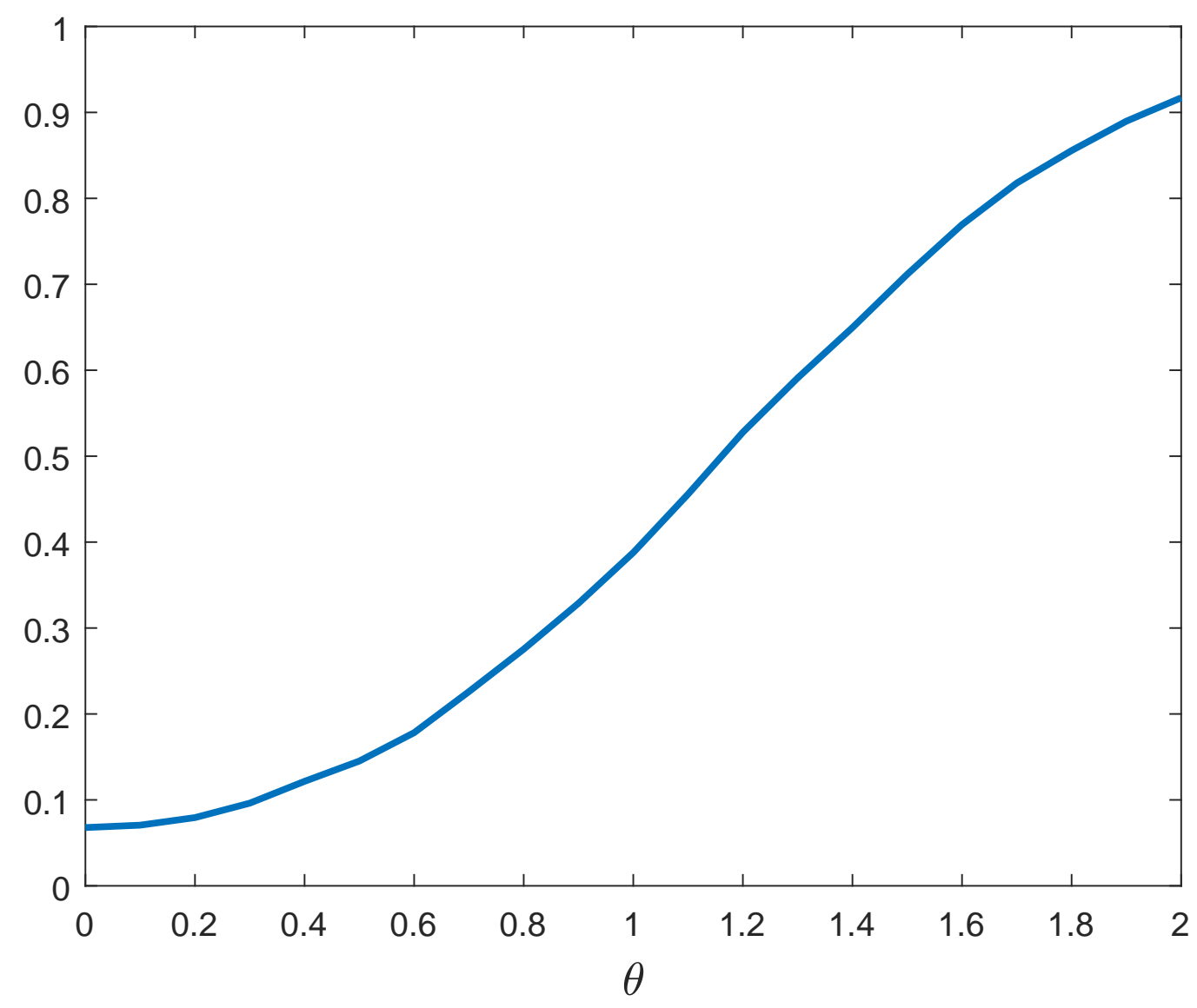

Notes: This figure plots the simulated power curves of the Wald test for seasonality when data are generated by the data generating process in equations (3.2)-equation (3.4). The sample size is $T=64$ and the lag truncation parameter is set to $1.3 T^{1 / 2}$ with the $p$-values of Kiefer and Vogelsang (2005). 
Table 1: Real GDP Growth Rates by Quarter 2014Q1-2018Q2

\begin{tabular}{cccc}
\hline \hline & BEA: Pre-Rev & BEA Post-Rev & Direct \\
2014Q1 & -0.9 & -1.0 & 1.1 \\
2014Q2 & 4.6 & 5.1 & 1.4 \\
2014Q3 & 5.2 & 4.9 & 5.0 \\
2014Q4 & 2.0 & 1.9 & 3.3 \\
2015Q1 & 3.2 & 3.3 & 3.6 \\
2015Q2 & 2.7 & 3.3 & 2.6 \\
2015Q3 & 1.6 & 1.0 & 1.1 \\
2015Q4 & 0.5 & 0.4 & -0.5 \\
$2016 Q 1$ & 0.6 & 1.5 & 1.2 \\
$2016 Q 2$ & 2.2 & 2.3 & 3.3 \\
2016Q3 & 2.8 & 1.9 & 1.1 \\
2016Q4 & 1.8 & 1.8 & 3.2 \\
2017Q1 & 1.2 & 1.8 & 0.2 \\
2017Q2 & 3.1 & 3.0 & 3.9 \\
2017Q3 & 3.2 & 2.8 & 3.4 \\
2017Q4 & 2.9 & 2.3 & 2.9 \\
2018Q1 & 2.0 & 2.2 & 3.1 \\
2018Q2 & & 4.1 & 4.0 \\
\hline \hline
\end{tabular}

Notes: This table reports the real GDP growth by quarter from 2014Q1-2018Q2 calculated (i) using data just before the 2018 benchmark revision, (ii) using the 2018 benchmark revision data, (iii) using data directly seasonally adjusted by me over the post-2002 period. Data are expressed as quarter-over-quarter annualized growth rates, in percentage points. 
Table 2: Average Growth Rates by Quarter: 2002Q1-2018Q1

\begin{tabular}{lcccc|cccc|cccc}
\hline \hline & \multicolumn{3}{c}{ BEA: Pre-Revision } & \multicolumn{3}{c}{ BEA: Post-Revision } & \multicolumn{4}{c}{ Direct SA } \\
& Q1 & Q2 & Q3 & Q4 & Q1 & Q2 & Q3 & Q4 & Q1 & Q2 & Q3 & Q4 \\
\hline Real GDP & 1.1 & 2.4 & 2.4 & 1.8 & 1.5 & 2.4 & 2.2 & 1.9 & 2.1 & 2.0 & 2.1 & 2.1 \\
Consumption & 2.0 & 2.2 & 2.4 & 2.2 & 2.0 & 2.2 & 2.6 & 2.1 & 2.2 & 2.2 & 2.2 & 2.2 \\
Durables & 4.3 & 5.9 & 7.3 & 2.7 & 4.1 & 5.4 & 7.4 & 2.4 & 5.8 & 5.4 & 3.8 & 3.9 \\
Nondurables & 2.0 & 1.5 & 1.6 & 2.8 & 2.1 & 1.3 & 1.5 & 2.3 & 2.2 & 2.1 & 2.0 & 1.3 \\
Services & 1.6 & 1.8 & 1.9 & 2.1 & 1.6 & 1.9 & 2.1 & 2.1 & 1.9 & 1.9 & 2.0 & 1.9 \\
GPDI & 0.3 & 3.9 & 3.4 & 3.7 & 1.1 & 4.5 & 4.1 & 4.2 & 3.2 & 3.0 & 3.6 & 4.7 \\
Structures & 0.9 & 5.9 & 0.5 & -1.7 & 2.6 & 5.5 & 5.4 & 2.4 & 1.8 & 0.5 & 0.9 & 1.3 \\
Equipment & 3.5 & 4.8 & 6.7 & 2.3 & -0.5 & 6.1 & 1.2 & -1.4 & 5.9 & 4.6 & 5.0 & 5.8 \\
Int Prop & 3.8 & 3.6 & 4.5 & 4.1 & 4.1 & 6.2 & 8.2 & 2.9 & 4.9 & 4.6 & 4.8 & 4.8 \\
Residential & 0.1 & 1.4 & -0.5 & 1.3 & 3.9 & 4.8 & 5.3 & 5.5 & -0.1 & 3.1 & -0.8 & -0.1 \\
Exports & 2.0 & 6.1 & 4.0 & 6.6 & 2.2 & 6.2 & 4.4 & 6.4 & 5.3 & 4.0 & 4.3 & 5.0 \\
Imports & 2.2 & 4.7 & 3.2 & 5.2 & 2.0 & 4.8 & 4.7 & 5.1 & 3.9 & 4.2 & 4.0 & 4.0 \\
Government & -0.5 & 1.9 & 1.1 & -0.1 & 0.6 & 1.2 & 0.3 & 0.5 & 0.8 & 0.7 & 0.7 & 0.7 \\
Fed Defense & -2.3 & 5.8 & 4.0 & -0.9 & 0.9 & 3.3 & 0.5 & 1.0 & 1.4 & 1.6 & 1.6 & 1.3 \\
Fed Non Defense & 3.3 & 1.5 & 0.7 & 2.5 & 3.4 & 1.7 & 0.9 & 2.8 & 2.0 & 2.6 & 2.5 & 2.3 \\
State and Local & -0.5 & 0.7 & 0.1 & -0.2 & -0.2 & 0.4 & 0.1 & -0.1 & 0.3 & 0.0 & 0.1 & 0.2 \\
Price Indices & & & & & & & & & & & & \\
GDP & 2.1 & 2.0 & 2.0 & 1.7 & 1.8 & 2.0 & 2.1 & 1.8 & 1.9 & 2.0 & 1.9 & 1.9 \\
PCE & 1.8 & 2.1 & 2.2 & 1.4 & 1.8 & 2.1 & 2.1 & 1.4 & 2.0 & 1.9 & 1.9 & 1.6 \\
Core PCE & 1.8 & 1.9 & 1.7 & 1.6 & 1.8 & 1.8 & 1.6 & 1.7 & & & & \\
\hline \hline
\end{tabular}

Notes: This table reports the average values by quarter from 2002Q1-2018Q1 of 19 series as described in the text. GPDI stands for Gross Private Domestic Investment and Int Prop stands for Intellectual Property. For each series, the averages are calculated (i) using data just before the 2018 benchmark revision, (ii) using the 2018 benchmark revision data, (iii) using data directly seasonally adjusted by me over the post- 2002 period. All series are expressed as quarter-overquarter annualized growth rates, in percentage points. Core PCE is not available for the direct seasonal adjustment because it is not published in NSA form. 
Table 3: Properties of Seasonally Adjusted Series

\begin{tabular}{lccc|ccc|ccc}
\hline \hline & \multicolumn{3}{c}{ BEA: Pre-Revision } & \multicolumn{3}{c}{ BEA: Post-Revision } & \multicolumn{3}{c}{ Direct SA } \\
& SD & $\hat{\rho}_{1}$ & $\hat{\rho}_{4}$ & SD & $\hat{\rho}_{1}$ & $\hat{\rho_{4}}$ & SD & $\hat{\rho}_{1}$ & $\hat{\rho}_{4}$ \\
\hline Real GDP & 2.37 & 0.45 & 0.07 & 2.34 & 0.41 & 0.02 & 2.35 & 0.46 & -0.07 \\
Consumption & 1.84 & 0.60 & 0.28 & 1.82 & 0.51 & 0.27 & 1.59 & 0.86 & 0.37 \\
$\quad$ Durables & 7.69 & 0.15 & 0.12 & 7.92 & 0.14 & 0.07 & 6.19 & 0.50 & 0.08 \\
Nondurables & 2.45 & 0.29 & 0.20 & 2.36 & 0.39 & 0.24 & 2.44 & 0.47 & 0.21 \\
Services & 1.31 & 0.72 & 0.33 & 1.25 & 0.56 & 0.28 & 1.12 & 0.74 & 0.32 \\
GPDI & 12.1 & 0.48 & -0.13 & 12.5 & 0.42 & -0.14 & 12.7 & 0.46 & -0.10 \\
Structures & 14.0 & 0.46 & 0.09 & 7.63 & 0.65 & 0.07 & 12.9 & 0.65 & 0.04 \\
Equipment & 12.4 & 0.54 & -0.04 & 13.9 & 0.49 & 0.07 & 11.6 & 0.74 & -0.14 \\
Int Prop & 3.95 & 0.17 & 0.00 & 12.1 & 0.63 & -0.09 & 3.02 & 0.49 & -0.10 \\
Residential & 14.9 & 0.54 & 0.38 & 5.10 & 0.04 & -0.03 & 15.0 & 0.49 & 0.43 \\
Exports & 8.02 & 0.42 & -0.11 & 8.13 & 0.42 & -0.09 & 7.94 & 0.45 & -0.09 \\
Imports & 8.36 & 0.53 & -0.07 & 8.20 & 0.56 & -0.08 & 6.92 & 0.81 & -0.17 \\
Government & 2.62 & 0.37 & 0.49 & 2.42 & 0.50 & 0.40 & 2.25 & 0.75 & 0.37 \\
Fed Defense & 8.09 & -0.01 & 0.31 & 6.18 & 0.14 & 0.28 & 5.03 & 0.57 & 0.39 \\
Fed Non Defense & 5.48 & 0.19 & 0.03 & 5.34 & 0.16 & 0.03 & 6.11 & 0.37 & 0.09 \\
State and Local & 2.14 & 0.44 & 0.25 & 2.24 & 0.57 & 0.21 & 2.37 & 0.58 & 0.18 \\
Price Indices & & & & & & & & & \\
GDP & 0.97 & 0.45 & 0.36 & 0.98 & 0.44 & 0.33 & 0.80 & 0.74 & 0.41 \\
PCE & 1.62 & 0.29 & -0.10 & 1.69 & 0.28 & -0.09 & 1.68 & 0.29 & -0.08 \\
Core PCE & 0.55 & 0.34 & -0.05 & 0.59 & 0.34 & -0.06 & & & \\
\hline \hline
\end{tabular}

Notes: This table reports the sample standard deviation and first and fourth autocorrelations from 2002Q1-2018Q1 of 19 series as described in the text. GPDI stands for Gross Private Domestic Investment and Int Prop stands for Intellectual Property. For each series, the statistics are calculated (i) using data just before the 2018 benchmark revision, (ii) using the 2018 benchmark revision data, (iii) using data directly seasonally adjusted by me over the post-2002 period. All series are expressed as quarter-over-quarter annualized growth rates, in percentage points. Core PCE is not available for the direct seasonal adjustment because it is not published in NSA form. 
Table 4: Wald test $p$ values for residual seasonality

\begin{tabular}{lccc}
\hline \hline & BEA: Pre-Rev & BEA Post-Rev & Direct \\
Real GDP & 0.18 & 0.66 & 0.98 \\
Consumption & 0.68 & 0.48 & 1.00 \\
Durables & 0.50 & 0.48 & 0.74 \\
Nondurables & 0.45 & 0.40 & 0.80 \\
Services & 0.43 & 0.34 & 0.98 \\
GPDI & 0.63 & 0.80 & 0.95 \\
Structures & 0.00 & 0.05 & 1.00 \\
Equipment & 0.48 & 0.00 & 0.87 \\
Int Prop & 0.89 & 0.27 & 0.94 \\
Residential & 0.86 & 0.92 & 0.79 \\
Exports & 0.22 & 0.27 & 0.97 \\
Imports & 0.43 & 0.42 & 0.99 \\
Government & 0.11 & 0.39 & 1.00 \\
Fed Defense & 0.05 & 0.34 & 0.99 \\
Fed Non Defense & 0.29 & 0.24 & 1.00 \\
State and Local & 0.59 & 0.81 & 1.00 \\
Price Indices & & & \\
GDP & 0.26 & 0.54 & 0.83 \\
PCE & 0.57 & 0.70 & 0.68 \\
Core PCE & 0.22 & 0.35 & \\
\hline \hline
\end{tabular}

Notes: This table reports the $p$-values from Wald tests for residual seasonality in equation (3.1). GPDI stands for Gross Private Domestic Investment and Int Prop stands for Intellectual Property. The lag truncation parameter is set to $1.3 T^{1 / 2}$ and the $p$-values of Kiefer and Vogelsang (2005) are used. The tests are run over the 2002Q1-2018Q1 period, using the three different seasonally adjusted series. Core PCE is not available for the direct seasonal adjustment because it is not published in NSA form. 
Table 5: $p$ values from tests of constancy of seasonal pattern in seasonally adjusted data

\begin{tabular}{lccc}
\hline \hline & BEA Pre-Rev & BEA Post-Rev & Direct \\
Real GDP & 0.60 & 0.22 & 0.77 \\
Consumption & 0.02 & 0.07 & 0.79 \\
Durables & 0.01 & 0.03 & 0.68 \\
Nondurables & 0.25 & 0.30 & 0.71 \\
Services & 0.65 & 0.55 & 0.82 \\
GPDI & 0.61 & 0.50 & 0.61 \\
Structures & 0.21 & 0.52 & 0.56 \\
Equipment & 0.54 & 0.18 & 0.59 \\
Int Prop & 0.16 & 0.47 & 0.70 \\
Residential & 0.48 & 0.18 & 0.37 \\
Exports & 0.42 & 0.50 & 0.32 \\
Imports & 0.59 & 0.51 & 0.73 \\
Government & 0.28 & 0.54 & 0.90 \\
Fed Defense & 0.04 & 0.18 & 0.25 \\
Fed Non Defense & 0.27 & 0.51 & 0.50 \\
State and Local & 0.34 & 0.49 & 0.23 \\
Price Indices & & & \\
GDP & 0.07 & 0.23 & 0.50 \\
PCE & 0.14 & 0.13 & 0.04 \\
Core PCE & 0.14 & 0.72 & \\
\hline \hline
\end{tabular}

Notes: This table reports the $p$-values from tests for time-varying residual seasonality comparing the test statistic in equation (3.5) with the limiting distribution in equation (3.6). GPDI stands for Gross Private Domestic Investment and Int Prop stands for Intellectual Property. The tests are run over the 2002Q1-2018Q1 period, using the three different seasonally adjusted series. Core PCE is not available for the direct seasonal adjustment because it is not published in NSA form. 
Table 6: $p$ values from joint test of stable and zero residual seasonality

\begin{tabular}{lccc}
\hline \hline & BEA Pre-Rev & BEA Post-Rev & Direct \\
Real GDP & 0.19 & 0.68 & 1.00 \\
Consumption & 0.67 & 0.47 & 1.00 \\
Durables & 0.49 & 0.47 & 0.77 \\
Nondurables & 0.45 & 0.41 & 0.82 \\
Services & 0.45 & 0.35 & 0.99 \\
GPDI & 0.65 & 0.83 & 0.97 \\
Structures & 0.00 & 0.06 & 1.00 \\
Equipment & 0.50 & 0.00 & 0.89 \\
Int Prop & 0.91 & 0.27 & 0.97 \\
Residential & 0.87 & 0.94 & 0.80 \\
Exports & 0.22 & 0.28 & 0.98 \\
Imports & 0.44 & 0.43 & 1.00 \\
Government & 0.11 & 0.39 & 1.00 \\
Fed Defense & 0.05 & 0.34 & 0.98 \\
Fed Non Defense & 0.29 & 0.25 & 1.00 \\
State and Local & 0.61 & 0.83 & 1.00 \\
Price Indices & & & \\
GDP & 0.26 & 0.54 & 0.85 \\
PCE & 0.56 & 0.69 & 0.67 \\
Core PCE & 0.22 & 0.36 & \\
\hline \hline
\end{tabular}

Notes: This table reports the $p$-values from joint tests of stable and zero residual seasonality comparing the test statistic $W+L$ with the limiting distribution in equation (3.7). GPDI stands for Gross Private Domestic Investment and Int Prop stands for Intellectual Property. The tests are run over the 2002Q1-2018Q1 period, using the three different seasonally adjusted series. Core PCE is not available for the direct seasonal adjustment because it is not published in NSA form. 


\section{References}

BARSKY, R. B., AND J. A. Miron (1989): “The Seasonal Cycle and the Business Cycle,” Journal of Political Economy, 97, 503-534.

Bloem, A. M., R. J. Dippelsman, And N. Ø. MÆHle (2001): Quarterly National Accounts Manual: Concepts, Data Sources, and Compilation. IMF.

Boldin, M., AND J. H. WRight (2016): “Weather-Adjusting Economic Data," Brookings Papers on Economic Activity, 2, 227-278.

Canova, F., And B. E. Hansen (1995): "Are Seasonal Patterns Constant over Time? A Test for Seasonal Stability," Journal of Business and Economic Statistics, 13, 237-252.

Cho, C.-K., AND T. J. Vogelsang (2017): "Fixed-b inference for testing structural change in a time series regression,” Econometrics, 5, 2.

Ghysels, E. (1988): "A Study Toward a Dynamic Theory of Seasonality for Economic Time Series," Journal of the American Statistical Association, 83, 168-172.

Gilbert, C., N. J. Morin, A. D. Paciorek, and C. R. SAhm (2015): "Residual Seasonality in GDP,” Board of Governors of the Federal Reserve System, FEDS Notes.

GÓmEz, V., AND A. MARAVALl (1996): "Programs TRAMO and SEATS. Instructions for the User," Working Paper 9628, Servicio de Estudios, Banco de España.

- (2013): "Automatic modeling methods for univariate time series," in A Course in Time Series Analysis, ed. by D. Peña, G. C. Tiao, and R. S. Tsay. J. Wiley and Sons.

Groen, J., And P. Russo (2015): “The Myth of First-Quarter Residual Seasonality,” Federal Reserve Bank of New York, Liberty Street Economics Blog.

Hansen, L. P., and T. J. SARgent (1993): "Seasonality and Approximation Errors in Rational Expectations Models,” Journal of Econometrics, 55, 21-55.

Kiefer, N. M., And T. J. Vogelsang (2005): "A new asymptotic theory for heteroskedasticityautocorrelation robust tests," Econometric Theory, 21, 1130-1164.

Landefeld, J. S., E. P. Seskin, and B. M. Fraumeni (2008): "Taking the Pulse of the Economy: Measuring GDP," Journal of Economic Perspectives, 22, 193-216.

LaZARUs, E., D. J. Lewis, J. H. STOCK, And M. W. WATson (forthcoming): "HAR Inference: Recommendations for Practice," Journal of Business and Economic Statistics.

Lothian, J., And M. Morry (1978): "A Set of Quality Control Statistics for the X-11 ARIMA Seasonal Adjustment Method," Statistics Canada Working Paper 78-10-005E.

LUnSFORD, K. G. (2017): "Lingering Residual Seasonality in GDP Growth,” Federal Reserve Bank of Cleveland, Economic Commentary. 
Maravall, A. (1995): “Unobserved Components in Economic Time Series," in The Handbook of Applied Econometrics, ed. by H. Pesaran, and M. Wickens. Basil Blackwell.

(2006): "An application of the TRAMO-SEATS automatic procedure; direct versus indirect adjustment," Computational Statistics and Data Analysis, 50.

McCulla, S. H., AND S. Smith (2015): “The 2015 Annual Revision of the National Income and Product Accounts," Survey of Current Business, 95:8.

McDonald-Johnson, K. M., B. Monsell, R. Fescina, R. Feldpausch, C. C. H. Hood, and M. Wroblewski (2010): “Census Bureau Guideline: Seasonal Adjustment Diagnostics,” Manuscript, US Census Bureau.

Moulton, B. R., And B. D. CowAn (2016): "Residual Seasonality in GDP and GDI: Findings and Next Steps,” Survey of Current Business, 96:7.

Nyblom, J. (1989): “Testing for the Constancy of Parameters Over Time," Journal of the American Statistifcal Association, 84, 223-230.

PeneVA, E. (2014): "Residual Seasonality in Core Consumer Price Inflation," Board of Governors of the Federal Reserve System, FEDS Notes.

PhilliPs, K. R., AND J. WANG (2016): “Residual Seasonality in U.S. GDP Data,” Federal Reserve Bank of Dallas Working Paper 1608.

Rudebusch, G. D., D. Wilson, and T. Mahedy (2015): “The Puzzle of Weak First-Quarter GDP Growth," Federal Reserve Bank of San Francisco, Economic Letter.

SAIJO, H. (2013): "Estimating DSGE models using seasonally adjusted and unadjusted data," Journal of Econometrics, 173, 22-35.

SIMS, C. A. (1993): "Rational Expectations Modeling with Seasonally Adjusted Data," Journal of Econometrics, 55, 9-19.

STARK, T. (2015): "First Quarters in the National Income and Product Accounts," Federal Reserve Bank of Philadelphia, Research Rap Special Report.

Wright, J. H. (2013): “Unseasonal Seasonals?,” Brookings Papers on Economic Activity, 2, 65110.

(2017): “Optimal Seasonal Filtering,” Manuscript, Johns Hopkins University. 